\title{
Low income mothers of overweight children had personal and environmental challenges in preventing and managing obesity
}

\author{
Jain A, Sherman SN, Chamberlin LA, et al. Why don't low-income mothers worry about their preschoolers being \\ overweight? Pediatrics 2001 May;107:1138-46.
QUESTIONS: What are the perceptions of low income mothers about their overweight preschool children? What barriers exist to the prevention or management of childhood obesity?

\section{Design \\ Qualitative study using focus groups.}

\section{Setting}

Clinic of the Special Supplemental Nutrition Program for Women, Infants, and Children (WIC) in Cincinnati, Ohio, USA.

\section{Patients}

18 mothers (mean age 25 y, $72 \%$ black) of preschool children (mean age 44 mo, 61\% girls) were enrolled in a nutrition clinic for women and their children living in low income households. 12 of the mothers $(67 \%)$ were obese (body mass index $[\mathrm{BMI}] \geqslant 30 \mathrm{~kg} / \mathrm{m}^{2}, 4$ were overweight (BMI $\geqslant 25 \mathrm{~kg} / \mathrm{m}^{2}$ ), and 2 were neither overweight nor obese. All of the children had a weight for height percentile $(\mathrm{WHP}) \geqslant 50^{\text {th }}$ percentile; $15(83 \%)$ met the WIC definition of overweight (WHP $\geqslant 90^{\text {th }}$ percentile).

\section{Methods}

Mothers participated in a 1 hour focus group ( 6 women per group). Open ended (root) and specific (probe) questions were used to explore how mothers defined overweight (definition), how they thought their children became overweight (aetiology), and what barriers existed to preventing or managing childhood obesity (management). Focus group sessions were audiotaped, transcribed, and reviewed for recurrent themes.

\section{Main findings}

10 major themes emerged from the focus groups. Definition (4 themes): (1) mothers felt that standardised growth charts did not define a healthy weight; (2) they referred to their child's size as being "solid", "thick", or "strong" and described size in terms of bone structure, frame, and clothing size; (3) mothers considered their children overweight if they were inactive, lazy, or were teased about their weight; and (4) mothers did not consider their children overweight if they were active, playful, and had good appetites. Aetiology (2 themes): (1) mothers believed that nature, genetics, and heredity determined weight and height in children; (2) they also felt that parental behaviours and family environment influenced eating and activity habits. Management (4 themes): (1) mothers reported having trouble controlling their children's eating habits because they were unable or did not wish to deny them food; (2) food was used by some mothers to reward good behaviour in their children; (3) mothers' control of their children's diet was challenged by other family caregivers; and (4) mothers' own obesity affected their outlook in managing their children's weight.

\section{Conclusions}

Low income mothers of overweight preschool children did not find paediatric growth charts useful in defining their children's weight. Physical activity and a good appetite were more important to the mothers as indicators of good health. Mothers felt that their children's weight was predestined by heredity and expressed difficulty in structuring their children's eating habits.
Source of funding: US Department of Agriculture, Food and Nutrition Service.

For correspondence: Dr A Jain, Department of Pediatrics, University of Chicago Children's Hospital, 5841 South Maryland Avenue, $M C$ 6082, Chicago, IL 60637,USA.ajain@ peds.bsd.uchicago.edu.

\section{COMMENTARY}

Jain et al contribute key information to understanding perceptions of childhood obesity in low income mothers. Consistent with an earlier study by several of Jain's team members, ${ }^{1}$ mothers from low socio economic levels who acknowledged themselves as overweight tended to not see their preschool children as overweight. Rather, for these mothers, the designation of a child being overweight based on standard growth charts was irrelevant if the child was active and had no functional limitations.

Although the authors acknowledged the limitations because of the small sample size and composition of predominantly urban, low income, obese mothers and preschool children, valuable insight is gained about the reasons these mothers are not more concerned about their children's excess weight. The use of focus group interviews permitted clarification of maternal perceptions of obesity.

A tendency toward childhood obesity has previously been linked to parental use of food to satisfy children's emotional needs or reward good behaviour. ${ }^{2}$ Similar to a review by Baskin $e t a l,{ }^{3}$ Jain $e t ~ a l$ address the need to explore cultural views about body size and image and intergenerational influences on feeding. The findings suggest several strategies to consider when low income families at risk for childhood obesity are taught and counselled. These strategies may include involving grandmothers, identifying practical means for controlling food intake, and not relying extensively on growth charts as teaching aids. The national upsurge in paediatric obesity is leading to younger children being diagnosed with type 2 diabetes, particularly in minority populations. ${ }^{4}$ In an attempt to minimise early diagnosis of type 2 diabetes and other complications, the challenge remains to identify strategies for obesity prevention and treatment that are individualised for vulnerable children and their families.

Melissa Spezia Faulkner, RN, DSN Associate Professor, Department of Maternal-Child Nursing University of Illinois at Chicago Chicago, Illinois, USA

1 Baughcum AE, Chamberlin LA, Deeks CM, et al. Maternal perceptions of overweight preschool children. Pediatrics 2000;106:1380-6.

2 Baughcum AE, Burklow KA, Deeks CM, et al. Maternal feeding practices and childhood obesity: a focus group study of low-income mothers. Arch Pediatr Adolesc Med 1998;152:1010-4.

3 Baskin ML, Ahluwalia HK, Resnicow K. Obesity intervention among African-American children and adolescents. Pediatr Clin North Am 2001;48:1027-39.

4 Rosenbloom AL, Joe JR, Young RS, et al. Emerging epidemic of type 2 diabetes in youth. Diabetes Care 1999;22:345-54. 